University of Wollongong

Research Online

Faculty of Arts, Social Sciences and Humanities

- Papers

Faculty of Arts, Social Sciences \& Humanities

$1-1-2020$

Rethinking respite in Australia: a naturalistic effect study of a multicomponent community program to promote respite knowledge, attitudes and behaviours of carers of people with dementia

Lyn Phillipson

University of Wollongong, Iphillip@uow.edu.au

Keryn M. Johnson

University of Wollongong, kerynj@uow.edu.au

Elaine Fielding

Elizabeth Preston

University of Wollongong, Icridlan@uow.edu.au

Danika Hall

University of Wollongong, danika@uow.edu.au

See next page for additional authors

Follow this and additional works at: https://ro.uow.edu.au/asshpapers

Research Online is the open access institutional repository for the University of Wollongong. For further information contact the UOW Library: research-pubs@uow.edu.au 


\title{
Rethinking respite in Australia: a naturalistic effect study of a multicomponent community program to promote respite knowledge, attitudes and behaviours of carers of people with dementia
}

\begin{abstract}
'Rethink Respite' was a prospective, naturalistic cohort study conducted in the Illawarra-Shoalhaven (NSW, Australia) to improve knowledge, attitudes and uptake of respite strategies in carers of people with dementia. A convenience sample of $n=70$ carers were recruited in 2014-15 to establish a baseline for knowledge, attitudes and use of respite for a cohort of carers in the region. Carer perceived need for respite, burden and self-efficacy were also assessed. A co-designed multi-component community-based intervention was subsequently rolled at in the region from 2015 to 2016. The intervention supported: awareness raising media; carer education sessions; access to web and print respite information resources; and an option to participate in a tailored one-on-one in-home coaching program. At program completion, a follow-up survey was administered to the cohort, with $n=44 / 70$ responding. All $n=44$ respondents reported participation in and exposure to 'Rethink Respite' media, information and education during the intervention period. Eighteen of the 44 also self-selected to receive the active tailored coaching support. At follow-up, few positive results were reported on the assessed carer variables for the cohort over time. However, post hoc sub-group analyses found those who also self-selected to receive active support (provided through coaching) $(n=18)$, showed improvements to their respite knowledge, attitudes and self-efficacy $(p<.05)$. Intention to use respite, and levels of personal gain from caring in this sub-group also increased $(p<.05)$. In contrast, carers who only participated in the informational/ educational aspects of the program (and did not self-select to the respite coaching), experienced negative changes over time to their respite beliefs and 'role captivity'. Overall, this pilot study suggests that passive respite information and educational strategies are insufficient, without more active supports (tailored respite coaching) to address observed carer decline over time. Future research should seek to replicate these results using a larger sample and an experimental design.

\section{Publication Details}

Phillipson, L., Johnson, K., Fielding, E., Cridland, E., Hall, D., Neville, C. \& Hasan, H. (2020). Rethinking respite in Australia: a naturalistic effect study of a multicomponent community program to promote respite knowledge, attitudes and behaviours of carers of people with dementia. Health and Social Care in the Community, Online First 1-18.
\end{abstract}

\section{Authors}

Lyn Phillipson, Keryn M. Johnson, Elaine Fielding, Elizabeth Preston, Danika Hall, Christine Neville, and Helen M. Hasan

This journal article is available at Research Online: https://ro.uow.edu.au/asshpapers/390 
Authors: Phillipson, L., Johnson, K., Fielding, E., Cridland, E., Hall, D., Neville, C., and Hasan, $\mathrm{H}$.

Title: Rethinking respite in Australia: a naturalistic effect study of a multicomponent community program to promote respite knowledge, attitudes and behaviours of carers of people with dementia.

Published in: Health and Social Care in the Community. (Early view). Accepted 8 October 2020. DOI: $10.1111 /$ hsc. 13223 


\begin{abstract}
'Rethink Respite' was a prospective, naturalistic cohort study conducted in the IllawarraShoalhaven (NSW, Australia) to improve knowledge, attitudes and uptake of respite strategies in carers of people with dementia. A convenience sample of $n=70$ carers were recruited in 2014-15 to establish a baseline for knowledge, attitudes and use of respite for a cohort of carers in the region. Carer perceived need for respite, burden and self-efficacy were also assessed. A co-designed multi-component community-based intervention was subsequently rolled at in the region from 2015 to 2016. The intervention supported: awareness raising media; carer education sessions; access to web and print respite information resources; and an option to participate in a tailored one-on-one in-home coaching program. At program completion, a follow up survey was administered to the cohort, with $n=44 / 70$ responding. All $n=44$ respondents reported participation in and exposure to 'Rethink Respite' media, information and education during the intervention period. Eighteen of the 44 also self-selected to receive the active tailored coaching support. At follow up, few positive results were reported on the assessed carer variables for the cohort over time. However, posthoc sub-group analyses found those who also self-selected to receive active support (provided through coaching) (n=18), showed improvements to their respite knowledge, attitudes and self-efficacy $(\mathrm{p}<0.05)$. Intention to use respite, and levels of personal gain from caring in this sub-group also increased $(\mathrm{p}<0.05)$. In contrast, carers who only participated in the informational/educational aspects of the program (and did not self-select to the respite coaching), experienced negative changes over time to their respite beliefs and 'role captivity'. Overall, this pilot study suggests that passive respite information and educational strategies are insufficient, without more active supports (tailored respite coaching) to address observed carer decline over time. Future research should seek to replicate these results using a larger sample and an experimental design.
\end{abstract}


Keywords: respite, carers, dementia, long term care, community care, social marketing

\section{What is known about this topic?}

- Carers of people with dementia report high need for respite

- Despite this, carers of people with dementia are low users of respite services

- Carers report poor experiences of help-seeking and quality and availability of respite

\section{What this paper adds?}

- Information and education alone are unlikely to change carer respite knowledge, attitudes or behaviours

- Intensive approaches such as coaching may be useful to support building knowledge and self-efficacy around respite

- However, despite some benefits, coaching alone may still be insufficient without other system reforms to increase use of respite services 


\section{Introduction}

\section{Problem Description and Available Knowledge}

There are an estimated 46.8 million people currently living with dementia worldwide (Alzheimer's Disease International, 2015). This number is expected to double every 20 years, meaning over 74 million people will be living with the condition by 2030 (Alzheimer's Disease International, 2015). People with dementia can benefit significantly from community level initiatives to live well (Alzheimer's Disease International, 2016) and from services to support wellbeing such as social support, transport, domestic assistance and personal care (Australian Institute of Health and Welfare, 2007). Family carers are also critical to supporting people with dementia to live at home, and those with a co-resident carer are more likely to be able to live at home for longer (Banerjee et al., 2003). Caring for someone with dementia can be a positive experience (Carbonneau, Caron, and Desrosiers, 2010). However, caring for someone with dementia is also associated with emotional, psychological, and physical impacts on carer health (Bertrand, Fredman, and Saczynski, 2006). As such, consideration of the impact of living with dementia on the care relationship and meeting the need of carers for quality flexible respite is essential (Bruen and Howe, 2009).

Respite services have traditionally been conceptualised as a break for carers and have been operationalised as substitute support arrangements (supporting the person with the disability in the home); centre based services (e.g., day activity centres); or, as a longer overnight care arrangement in a residential aged care facility or respite cottage (Petty, 1990). However, research into residential respite has highlighted carers' needs for 'more than a break' (Bruen and Howe, 2009). Individualised funding models have also shifted the focus of respite to the 
benefits for the person with disability, and the provision of a break as a secondary outcome for carers (Hamilton, Giuntoli, Johnson and Fisher, 2016).

Despite the potential benefits of respite, many people with dementia and their carers are reluctant to use respite services or strategies (Markle-Reid and Browne, 2001). Australian research estimates only around a third of carers use available respite services (Bruen and Howe, 2009). Commonly reported barriers to use include: resistance from the person with dementia; lack of awareness about services/strategies; practical challenges (e.g., transport, costs, difficulties organising services); perceptions of poor quality; and previous negative experiences (Brodaty, Thomson, Thompson and Fine, 2005; Ho, Mak, Kwok, Au and Ho, 2015; Phillipson, Jones, \& Magee, 2014; Phillipson, Magee, \& Jones, 2013; Robinson et al., 2012). Further, some carers associate the use of respite with guilt and/or 'failure' of not fulfilling family responsibilities (Fielding, Beattie, Readford and Neville, 2012; Phillipson et al. 2014).

In Australia, access to a variety of respite service types is theoretically possible, through government funding. However, major reforms to the aged and disability systems, including a transition to Consumer Directed Care, have occurred since 2015. At the time of this study these required people with dementia and caregivers to negotiate with three different programs to access respite services: My Aged Care for planned respite services (Australian Government, 2017), Carelink and Carer Respite Centres (CCRC) for short term and emergency respite (Department Social Services 2018); and a Carer Gateway for information, education and counselling (Australian Government 2015). Low use of respite services since the introduced changes in the care systems in Australia has highlighted the need for effective interventions to support better access to quality respite for people living with dementia, and their carers (Phillipson, Low and Dreyfus, 2019). 


\section{Aims and Rationale}

'Rethink Respite' was a community based multi-component social marketing program that aimed to support access and utilisation of respite services and strategies by carers of people with dementia. It was developed based on formative research and co-design sessions with carers and service providers. It was implemented as part of a naturalistic cohort study in a single geographic area, in the Illawarra-Shoalhaven region, NSW, Australia, between February 2015 and December 2016. The research and implementation team included: academics from sociology, nursing, public health, social marketing, information systems, and psychology. The program logic for the model has been illustrated in Figure 1.

\section{Insert Figure 1 here}

Theory

The intervention was underpinned by Anderson's Behavioural Model of Health Service Use (Andersen, 1995), which proposes that service use is influenced by demographic; social structure and health beliefs (predisposing characteristics); community and personal resources (enabling or impeding factors); and evaluated and perceived need factors. This model is dominant in research examining factors influencing peoples access to health services (Ricketts and Goldsmith, 2005), and has also been used to explain factors associated with out of home respite service use by carers of people with dementia (Phillipson, Johnson, Cridland, Neville, Fielding and Hasan, 2019). Anderson's theory informed the selection of intervention components, ensuring relevant behavioural and social factors were targeted. The intervention targeted carers with an evaluated and/or perceived need for respite. It supported the development and dissemination of: media and education to promote positive respite knowledge and beliefs; resources to enable respite access; and, the provision of support for carer skills to set respite goals and navigate the service system to meet their respite needs. 


\section{Description of the Intervention}

Strategies and resources were co-designed with a carer and a service provider advisory group and included: the 'Rethink Respite' website and resources; the conduct of a communication and education campaign, service development workshops and individualised Respite Coaching.

'Rethink Respite' website and resources - A tailored, localised website (www.rethink respite.com) provided informational and navigational resources for people with dementia, carers, service providers and Primary Health Care Nurses (PHCNs). The website promoted respite as a resource for successful caring, and living well with dementia. It included: information on respite strategies and a directory of respite services in the region; a decision guide and checklists to aide choosing specific respite services; key contacts and support group lists; an events calendar and news blog; a carer discussion forum; and videos of people with dementia and carers discussing their positive respite experiences. Printable versions of key resources were available to download and were promoted to PHCNs, Aged Care Assessment Teams (ACATs) and service providers to distribute to their clients. Prior to rollout, the website was tested with four carers of people with dementia in a usability testing laboratory. Improvements were made to navigation and design features.

Communications and education campaign - A targeted communications campaign included TV news, aged sector news, community radio, community events and presentations, website blogs, Twitter feeds and participant newsletters. Tailored presentations were a primary channel for education regarding the benefits of planning respite early, distributing resources and materials, and promoting the website and Respite Coaching program. A total of 21 community education sessions were conducted including eight presentations to persons with dementia client groups and carers Carer Support Groups (102 PWD and carers); 10 service 
provider groups (141 individuals); two Primary Health Care Nurse networks (26 PHCN) and one older age community group (68 individuals).

'Rethink Respite' Newsletters - Five newsletters were distributed to 145 people, including baseline survey participants, stakeholders, service providers and community members. These promoted 'Rethink Respite' activities and resources, positive respite messages and relevant local events and how to access the Respite coaching program.

Service Development Workshops - Four workshops with $n=26$ participants provided information about the features of quality respite services for people with dementia and their carers, tools to audit the quality of service, and brainstorming activities to identify strategies for improving quality and flexibility of services.

Respite Coaching - Individualised support for the person with dementia and their carers was also offered to all baseline respondents via the 'Rethink Respite' Coaching program. This goal orientated program was developed specifically for the project based on formative research. It was delivered by health professionals at a time and location convenient for the participants (e.g., their home or community location). Program components included identification and enhancement of personal strengths and values; support to set goals around respite use; discussion about types respite; support to navigate the online My Aged Care service directory; and practice of respite strategies such as mindfulness and communication skills. The program typically involved eight sessions with a respite coach and comprised six to eight modules based on the participant's respite goals.

\section{Methods}

\section{Evaluation Framework}


A logic model (Figure 1) was used to optimise and monitor implementation integrity. This model highlights how intervention activities/strategies were designed to increase carer knowledge of local respite services, improve beliefs about the benefits of respite and respite services, and improve self-efficacy for finding information about, and accessing, respite services. It was hypothesised that this would also lead to increased use of respite and intentions to use respite, as well as reducing unmet need for respite in the local community.

To evaluate the impact we conducted a naturalistic effect evaluation (Windhorst et al. 2019), where resources were offered to participants who then accessed and used the components they felt relevant to them, including the respite coaching. This use of this model precludes randomisation, and does not allow standardisation of the intervention as needed in controlled trials (Green and South 2006). It does however, seek to determine the effectiveness of the intervention under 'real world' conditions (Green and South 2006). Evaluation methods included use a survey of in 2014-15 to establish a baseline for respite knowledge, attitudes and use of respite for a cohort of carers in the region. We repeated this survey, along with a process evaluation of website usage, respite coaching and service provider workshops at completion of the intervention. The follow-up survey was also used to establish exposure to the intervention in the cohort at follow-up.

Ethical Considerations: All participants in the study provided informed written consent. The study protocol and materials were reviewed and approved by the University Human Research Ethics Committee (HE15/027).

\section{Sample}

Paper surveys were distributed at Baseline (T1), using multiple local channels. These were mailed out to carers of older people with dementia who had made contact in the previous 12 months with the local branch on the National Commonwealth Respite and Carelink Centre 
(CRCC). Additional surveys were also distributed via assessment and, respite service providers, Carer Support Groups and at local events. A total of 494 paper-based surveys were distributed at baseline of which $n=84$ valid paper surveys were returned ( $18 \%$ response rate).

As part of the effect evaluation, respondents who completed a baseline survey, and indicated that they would be willing to complete a follow up survey (70/84), were sent a follow up survey during October, 2017 (T2). A second follow-up survey was sent two months later for non-responders, followed by a phone call if participants had provided a phone contact. Valid surveys were returned by 44/70 participants. However, a number of carers were lost to follow-up survey due to their family member or friend entering residential care $(n=10)$, had passed away $(n=5)$, or were themselves ill or indisposed (3). Fourteen declined follow-up for varying reasons, including time and carer pressures. No significant differences were found between those completing the follow-up survey and those who did not. This comparison included demographic variables (caregiver age, gender, relationship, language other than English), and formal and informal support, unmet need, member of a support group or previous caregiver training ( $a=05)$. See Figure 2 for a flowchart of survey response details.

\section{Insert Figure 2 here}

\section{Survey Instrument}

The survey tool was theoretically informed (Andersen, 1995) and included a number of standardised scales. Variables assessed: factors known to predispose service use including demographic characteristics (e.g. gender, age, education, languages others than English; caregiver relationship) as well as attitudes towards respite; enabling personal factors (e.g. 
financial, knowledge of respite services) and caring (e.g. personal gain). Enabling system factors which impact on service use were assessed (e.g. receiving caregiver training). Finally, carer's need for respite was assessed using both perceived and evaluated need variables including: measuring carer burden via the Zarit Burden scale (Bédard, Molloy, Squire, Dubois, Lever, and O’Donnell, (2001), and Role captivity scale (Pearlin, Mullan, Semple and Skaff, 1990); and self-efficacy through the Family Caregiver Self-efficacy for Managing Dementia scale (Fortinsky, Kercher and Burant, 2002). The Pearlin et al. (1990) Cognitive Status scale and Problematic Behaviour scale were also used as indirect measures of evaluated carer need for respite. Further questions were taken from previous respite research (Phillipson, et al. 2013) or developed specifically to assess self-efficacy for finding information about respite and where respondents looked for respite information. See Table 1.

\section{Insert Table 1 here}

\section{Data Analysis}

Data were analysed via IBM SPSS Statistics version 21. Comparison of respondents versus non-respondents was analysed by Chi Square Goodness of Fit Test. Analysis of changes over time from Baseline (T1) to Follow up (T2) were conducted through using McNemar Test of Change for categorical data, and paired t-tests or Wilcoxen Signed Rank Test as appropriate. Data imputation was conducted on three scales of Cognitive Status, Problematic Behaviour, and Self-Efficacy for Care, if $<20 \%$ missing data for each respondent. The mean score for that respondent on the specific scale was manually imputed. To examine whether there was an overall increase in intentions to use any of these respite services, a combined score was computed of day care, in-home and residential respite. As some respondents did not complete all sections of the question, missing data was handled by imputing a ' 3 ' which was neither 
likely nor unlikely. For this score, higher scores were indicative of being more likely to use these respite services.

\section{Post-hoc analyses}

Post-hoc analyses were also conducted to examine any differences between two sub-groups in the cohort - those who self-selected to participate in respite coaching compared to those who did not. As some differences between outcome variables were found, baseline characteristics of the two groups were analysed to examine whether this was due to baseline differences between these groups including: demographic variables, self-efficacy in caregiving, current use of respite, unmet need for respite, and attitudes, subjective norms and self-efficacy for finding respite services. Chi square or Fishers exact test for categorical data and independent t-tests or Mann Whitney U tests for ordinal and scale data were used, as appropriate. Results are shown for the total cohort, and the two post hoc sub-group analyses: Sub-Group 1 (those exposed to information and educational parts of the program) and Subgroup 2 (those who also participated in coaching).

\section{Results}

\section{Sample characteristics}

Of the forty four $(n=44)$ respondents to the follow up survey, $91 \%$ reported some exposure to the 'Rethink Respite' program activities or resources. Eighteen of those forty-four (41\%) also self-selected to participate in Respite coaching. Demographics and descriptors of the respondents at Follow up and the person they cared for (PWD) are shown in Table 2. 
Survey respondents were mostly female (75\%), with a mean age of 67.5 years (range 38-86). A majority (89\%) spoke English at home, had a spousal relationship (68\%), and co-resided with the person they cared for (96\%). At baseline, $60 \%$ received support from formal services, 54\% received support from family and friends, and 65\% reported an unmet need for respite. Sixty-one percent had previously attended caregiver training, and $56 \%$ were members of a carer support group. Of the people with dementia, most were male (58\%), with a mean age of 81 years (range 63 -94). A majority of those receiving care had a medical diagnosis (93\%), with Alzheimer's disease the most frequently nominated type of dementia (77\%).

\section{Baseline differences between Sub-Group 1 and Sub-Group 2}

To examine the characteristics of those who chose to participate in respite coaching and those who did not, we also examined any differences between sub-groups 1 and 2 . We found no significant differences regarding their demographic profiles or any variables related to carer need and burden. However, a significant difference was found for internet use with all subgroup 2 respondents using the internet to some degree, whereas eight sub-group 1 respondents did not use the internet $(\mathrm{p}=.014)$. Also, sub-group 2 participants who selfselected to take part in respite coaching were less likely to believe that respite was useful and beneficial for their family member or friend $(U=139.00, \mathrm{p}=.005)$, and had lower overall self-efficacy for caring for someone with dementia $(t(42)=-2.082, \mathrm{p}=.043)^{*}$. Analysis of individual items for caring self-efficacy showed sub-group 2 participants at baseline were significantly less confident that they could find ways to pay for services to help them care for their family member or friend $(U=152.00, \mathrm{p}=.047) *$. (*Data not shown in table).

\section{Exposure to the Intervention}

Our effect evaluation highlighted the effectiveness of the social marketing approach in the 'real-world' to reach our cohort of local carers of people with dementia. In our cohort, ninety- 
one percent of all respondents reported exposure to at least one component of 'Rethink Respite' at follow-up. However the level of exposure to individual components varied with $55 \%$ reporting exposure to brochures, $39 \%$ reporting exposure to the newsletters, and $5 \%$ reporting attendance at a community education session.

Post hoc analyses

A substantially higher proportion of sub-group 2 (respondents who received coaching) reported use of the website and service directory at $61 \%$ and $50 \%$ respectively, compared to sub-group 1 usage of $8 \%$ and $4 \%$. See Table 3.

Insert table 3 here

\section{Changes in predisposing beliefs about respite and perceived self-efficacy for finding respite information and services.}

No changes were found in predisposing beliefs and subjective norms about respite, or control beliefs about finding respite information and services for the total cohort.

Post hoc analyses

Sub-group 2 (coaching) respondents reported increased levels of personal gain from caring between Time 1 and Time $2(\mathrm{Z}=-2.543, \mathrm{p}=.011)$. This score included four Likert scale statements rated on how much they had become aware of their inner strengths, become more self-confident, grown as a person, and learned to do things they didn't do before. These respondents also reported significant changes over the intervention period with higher (more positive) beliefs that respite services are: 'useful and beneficial to my family member/friend' 
$(\mathrm{Z}=-2.157, \mathrm{p}=.031)$; and 'will assist me to provide care for longer' $(\mathrm{Z}=-2.111, \mathrm{p}=.035)$.

Significantly, sub-group 1 (exposed only to passive information strategies), reported lower (less positive) beliefs that respite services are 'useful and beneficial to my family member/friend' from baseline (T1) to post-intervention (T2) $(\mathrm{Z}=-1.977, \mathrm{p}=.048)$. See Table 4.

\section{Insert table 4}

With regards to carer perceived self-efficacy for accessing respite, no significant changes were seen from baseline to post-test for respondents from sub-group 1. However positive changes for sub-group 2 respondents who received coaching were evident for the statements 'if I want to, I can easily find information about respite services' $(Z=-2.807, p=.005)$ and 'if I want to, I can easily access the appropriate respite for the needs of my family member/friend' $(\mathrm{Z}=-1.994, \mathrm{p}=.046)$. See Table 4.

\section{Changes in enabling factors for seeking respite}

Increased knowledge and using more sources to find information about respite were regarded as enabling factors for respite use. Thirty-nine respondents reported looking for information in the past year, with a third of the cohort reporting looking for information on the program's website and service directory. See Table 5. Of other enabling factors, 36 caregivers reported having attended caregiver training in the past year, an additional nine respondents from baseline. See Table 6 .

\section{Post hoc analyses}

Slightly fewer sub-group 2 (coaching) respondents used the government website 'My Aged Care' - which is the single gateway service for information and referral for assessment for 
older people within Australia (9 vs 7 respectively), compared to Group 1 (4 vs 6 respectively). Slightly more people in both sub-groups (2 vs 6 respectively) and Group 1 (3 vs 5 respectively) reported using the 'My Aged Care' helpline than found at baseline. Confirming preferences for information sources reported at baseline, respondents tended to favour person-to-person sources of information to websites and helplines. See Table 5.

\section{Insert Table 5 here}

Over the intervention period, knowledge of local respite improved in sub-group 2 respondents compared to sub-group 1 respondents $(Z=-2.280, p=.023)$. At follow-up, subgroup 2 reported a significant increase in the number of sources they used for finding information about respite $(\mathrm{Z}=-2.449, \mathrm{p}=.014)$. This increase appeared to come largely from the use of the website and service directory by coaching participants. No changes over time were found for sub-group 1. Both sub-groups reported increased participation in caregiver training, with sub-group 2 (coaching) respondents showing a significance increase ( $\mathrm{p}=.031$, McNemar Test). No significant changes were found for use of formal or informal services from baseline to post-intervention for either sub-group. See Table 6.

\section{Insert table 6 here}

\section{Changes in Carer and PWD evaluated need over time}

No changes were found for the cohort's perceived level of burden, role captivity, or selfefficacy for care over the intervention period. Caregivers also did not report changes in assessed variables of caregiver need. Caregivers did however report using an increased number of 'types' of respite over the period $(\mathrm{Z}=-4.295, \mathrm{p}=.000)$.

Post hoc analyses 
Sub-group 1 respondents showed a decrease in their self-efficacy for care $(\mathrm{t}(24)=2.857, \mathrm{p}$ $=.009$ ). They also reported a significant decline in the cognitive status of the PWD that they were caring for over the intervention period $(\mathrm{Z}=-2.153, \mathrm{p}=.031)$. In contrast, Group 2 respondents reported an increase in self-efficacy for care over the same period $[\mathrm{t}(14)-2.321$, $\mathrm{p}=.036]$. Some significant changes were seen in current use of respite, in terms of the number of different respite services named by carers, for sub-group $2(\mathrm{Z}=-3.165, \mathrm{p}=.002)$ and subgroup $1(\mathrm{Z}=-2.942, \mathrm{p}=.003)$.

When examining intentions to use specific respite services, comparisons were made for a combined score of day care, in-home and residential care/respite cottage. Sub-group 2 (coaching) respondents reported more intentions to use respite $(Z=-2.028, p=.043)$, whereas sub-group 1 respondents reported a non-significant decrease in intentions $(Z=-1.127$, $\mathrm{p}=.260$ ). No significant changes were found for either group on unmet need for respite. See Table 7.

\section{Insert Table 7}

\section{Changes over the past year}

A qualitative question was asked of survey respondents, 'have you noticed any changes in respite services in the past year (e.g. cost, availability, quality)'. This question was answered by 30/44 respondents. Twelve respondents noted rising costs, and seven reported poorer availability of respite services. Four comments relayed concerns regarding the quality of respite services including: poor food quality, inappropriate use of medications and the inability of staff to communicate with a person with dementia who also spoke a language other than English. Five respondents noted no changes in the past year, although one 
comment described this as a lack of improvement in the quality of food or activities. Three positive comments were received with one respondent happy with her respite service over the past year, one noted more basic services being available, and another reported more available information regarding respite services. No differences were noted between groups for this question.

\section{Discussion}

'Re-Think Respite' aimed to encourage carers of people living with dementia to 'rethink' their beliefs about respite, and provide appropriate and timely information about the benefits of respite, available respite services, and help to choose and assess the right respite. The intention of the study was to co-develop and test a community based multicomponent intervention that could work in a 'real-world' setting to promote respite knowledge, attitudinal change and service use. Our carer and service provider advisory group were clear that people needed access to scaffolded supports - starting with information/education, tools and decision aids, and finally more intensive supports. In this study, we were not just testing the efficacy of a coaching intervention. Rather we were able to observe how carers in a realworld environment responded and made use of resources and supports being made available to them, and the extent to which these various levels of support impacted on their respite outcomes over time.

The intervention was conducted in Australia during a time of transition, with new service systems and gateway websites being established and amended over the period. These changes created challenges for our target audience in accessing up to date respite service information. However, the vast majority (91\%) of respondents reported exposure to one or more elements of 'Rethink Respite' which suggests the social marketing model may be an effective strategy to promote information access. 
Recall of exposure to printed brochures and newsletters was highest and websites the lowest. The low overall use of the internet by respondents is similar to other previous Australian research of older adults (Handley, Perkins, Kay-Lambkin, Lewin and Kelly, 2015).

Participation in coaching however, showed potential as a strategy to support utilisation of the website and service directory and also to increase the number of information sources used by carers of people to access respite information. However, it did not change use of MyAged care or other government sites. This may be due to the poor accessibility of the government aged care websites (Phillipson, Low and Dreyfus, 2019) as opposed to the 'Rethink Respite' website which was developed and tested using a co-design process.

Around one third of respondents also stated they had heard about 'Rethink Respite' through ACAT, PHC Nurses, geriatrician and service providers. Previous research has also shown carer preference for person-to-person information sources (Walker et al., 2017). This was evident in the current study, with baseline results $(n=84)$ showing that carers, in general, sought information from doctors, carer support groups, and family and friends in preference to helplines (next highest) or websites.

Overall, the value of utilising personal channels, as well as a variety of media channels to target a 'hard to reach' audience in the 'Rethink Respite' model was evident (Kotler and Lee 2008). Results from this intervention provide further evidence that putting information on websites will be insufficient to promote access. Rather, promotion and support will be needed via personal networks, health professionals and through coaching programs to support the use of internet based resources. This builds on the evidence for the utility of training programs to build skills in older adults to facilitate access to internet based information and support for service related decision making (Australian Seniors Clubs Association, 2017; Broadband for Seniors, 2017; National Seniors, 2017). 
That said, the benefits of coaching in this study appear to go beyond information access. The number of positive changes found for the respondents who had elected to receive personalised respite coaching (Group 2) is compelling. Results from the evaluation suggest the value of goal clarification for help-seeking. In the coaching intervention this occurred prior to attempts to navigate the system and helped carers to gain a greater sense of efficacy that they could both find services to support them, and that those services were potentially useful and beneficial to their needs.

Coaching participants also reported increases in 'personal gain' from caring, a scale that measures awareness of inner strengths, self-confidence and learning to do things they didn't do before. Through respite coaching, the person with dementia and their caregiver were encouraged to reflect on personal strengths and values to develop personal goals. From here, they were encouraged to consider how respite services and strategies (such as mindfulness and improved communication skills) may facilitate working towards these goals. As caregiving self-efficacy has been shown to be directly related to depression in dementia caregivers (Fortinsky et al., 2002; Gilliam and Steffen, 2006), this is an important factor in promoting caregiver wellbeing.

Whilst coaching appears to hold promise as a means to promote carer self-efficacy, we did not find any significant changes in respite behaviours or outcomes. Overall, despite gains in knowledge, attitudes and efficacy for coaching participants, carers in both groups reported a persistent unmet need for respite from baseline (68\%) to post-intervention (79\%). When respondents were asked about changes in the past year, problems such as rising costs, less availability and poor quality of respite services were offered as the reasons behind this. The high unmet need for respite services highlights challenges for the Aged Care system to promote access to appropriate high quality services. These difficulties may also be the result of a transition in Australia to an individualised care model, which focuses on the individual 
older person and as a consequence may fail to adequately assess and recognise the needs of carers (Duncan 2018).

\section{Limitations}

The researchers used a naturalistic study design in order to examine the intervention's effectiveness under 'real world' conditions (Green and South 2006). This does however preclude randomisation, as participants use the resources provided as they prefer, which means there is no standardisation of the intervention. This also means that it is difficult to determine whether any changes that occur, happen due to the intervention or other influences. This also is a small regional pilot study and may not be representative of carers in other parts of Australia.

Recruitment to the study was challenging due to the absence of national or state-based lists of carers of people with dementia living in the community. Previous research has also found low response rates for postal surveys to older populations (Palonen, Kaunonen and Åstedt-Kurki, 2016). Also, due to the nature of the dementia disease trajectory and the age of the target a high number were lost to the study through death or institutionalisation. Given these considerations, the estimated response rate of $18 \%$ appears reasonable. That said, the low sample numbers for the post-intervention survey would likely increase the likelihood of type 2 error, where significant changes are dismissed when they are, in fact, present. Stevens (1996) suggests when small group sizes (e.g. $\mathrm{n}=20$ ) are involved, it may be necessary to adjust alpha levels to .10 or .15 , however we have maintained a significance level of $p \leq .05$, but have not performed Bonferroni correction. These limitations suggest the need for the replication of the study with greater numbers and with the use of a control group.

\section{Conclusions}


This pilot study highlights the potential for tailored, motivational coaching to enhance community level activities to promote knowledge, confidence and skills relevant to seeking respite in carers of people with dementia. Respite coaching may also be useful to promote personal gain and reduce role captivity over time. However, more fundamental changes to the system are likely necessary to promote changes to respite behaviors and outcomes. Future research should seek to replicate these results using a larger sample and an experimental design.

\section{Declarations}

Conflict of Interest statement: The authors have no known conflicts of interest associated with this study

Funding: This study was funded by an Alzheimer's Australia Dementia Research Foundation and Resthaven Incorporated Grant. A/Prof Lyn Phillipson was also supported by a National Health and Medical Research Council Dementia Development Fellowship (APP1107401)

Ethics approval and consent to participate: The study protocol and materials were approved by the University of Wollongong Human Research Ethics Committee (HE15/027). All participants provided written consent.

Availability of data and materials: The datasets used and/or analysed during the current study are not publically available due to the conditions of the Human Ethics approval. Authors' contributions: LP was the lead investigator for the study and was primarily responsible for the study design and conduct and also the drafting of the manuscript. KJ was primarily responsible for the analysis of the survey data and also played a role in writing and editing the manuscript. EF contributed to the study design and provided statistical advice and guidance. EP was responsible with LP for the design of the Respite Coaching program. EF, $\mathrm{EP}, \mathrm{DH}, \mathrm{CN}$ and $\mathrm{HH}$ were all investigators on the project and contributed to the study design 
as well as to the editing and approval of the manuscript. All authors read and approved the final manuscript.

Acknowledgements: The authors wish to thank the local support services, carer support groups, carers and people with dementia in the Illawarra and Shoalhaven regions in NSW who participated in the research and supported the intervention activities.

\section{References}

Alzheimer's Disease International. (2015). World Alzheimer Report 2015: The Global Impact of Dementia - An analysis of prevalence, incidence, cost \& trends. Retrieved from London: https://www.alz.co.uk/research/WorldAlzheimerReport2015.pdf

Alzheimer's Disease International. (2016). World Alzheimer Report 2016: Improving healthcare for people living with dementia-Coverage, Quality and costs now and in the future. Retrieved from London: https://www.alz.co.uk/research/WorldAlzheimerReport2016.pdf

Australian Government (2015). Carer Gateway launched to help carers. Department of Social Services, Australian Government; 2015. Retrieved from: https://www.dss.gov.au/disability-and-carers/feature/carer-gateway-launched-to-helpcarers. Accessed: 20 December 2015

Australian Government (2017). Commonwealth Home Support Programme: Program manual 2017. Commonwealth of Australia, Department of Health. Retrieved from Australia: https://agedcare.health.gov.au/sites/g/files/net1426/f/documents/05_2017/chsp_manua 1_april_2017_final_0.pdf Accessed: 24 March 2018

Andersen, R. (1995). Revisiting the behavioral model and access to medical care: does it matter? Journal of Health and Social Behavior, 36(2), 1-10. doi: 10.2307/2137284 
Australian Institute of Health and Welfare. (2007). Dementia in Australia: National data analysis and development Retrieved from Canberra: AIHW.:

https://www.aihw.gov.au/reports/aged-care/dementia-australia-national-dataanalysis/contents/table-of-contents

Bédard, M., Molloy, D.W., Squire, L., Dubois, S., Lever, J.A., O’Donnell, M. (2001). The Zarit Burden Interview. The Gerontologist, 41, 652-657. doi:10.1093/geront/41.5.652

Banerjee, S., Murray, J., Foley, B., Atkins, L., Schneider, J., \& Mann, A. (2003). Predictors of institutionalisation in people with dementia. J Neurol Neurosurg Psychiatry, 74, 1315-1316. doi:http://dx.doi.org.ezproxy.uow.edu.au/10.1136/jnnp.74.9.1315

Bertrand, R. M., Fredman, L., \& Saczynski, J. (2006). Are all caregivers created equal? Stress in caregivers to adults with and without Dementia. Journal of Aging and Health, 18, 534-551. doi: 10.1177/0898264306289620

Brodaty, H., Thomson, C., Thompson, C., \& Fine, M. (2005). Why caregivers of people with dementia and memory loss don't use services. International Journal of Geriatric Psychiatry, 20(6), 537-546. doi:10.1002/gps.1322

Bruen, W., \& Howe, A. (2009). Respite care for people living with dementia: 'It's more than just a short break'. Retrieved from https://www.dementia.org.au/files/20090500_Nat_NP_17RespCarePplLivDem.pdf

Carbonneau, H., Caron, C., \& Desrosiers, J. (2010). Development of a conceptual framework of positive aspects of caregiving in dementia. Dementia, 9(3), 327-353. doi:10.1177/1471301210375316

Department of Social Services (2018). Commonwealth Respite and Carelink Centres. Australian Government. 2016. Retrieved from: https://www.dss.gov.au/disability-andcarers/programmes-services/for-carers/commonwealth-respite-and-carelink-centres Accessed: 24 March 2018 
Fielding, E., Beattie, E., Readford, M., \& Neville, C. (2012). Respite Care in Dementia: Carer Perspectives. Report on Full Study, 2012.Retrieved from http://www.dementiaresearch.org.au/index.php?option=com_dcrc\&layout=output\&oi $\underline{\mathrm{d}=641 \& \text { Itemid }=124}$

Fortinsky, R. H., Kercher, K., \& Burant, C. J. (2002). Measurement and correlates of family caregiver self-efficacy for managing dementia. Ageing and Mental Health 6, 153-160. doi:10.1080/13607860220126763

Gilliam, C., \& Steffen, A. (2006). The relationship between caregiving self-efficacy and depressive symptoms in dementia family caregivers. Aging \& Mental Health, 10, 7986. doi:10.1080/13607860500310658

Hamilton, M., Giuntoli, G., Johnson, K., \& Fisher, K. (2016). Transitioning Australian Respite. Retrieved from https://www.sprc.unsw.edu.au/media/SPRCFile/Transitioning_Australian_Respite.pdf Handley, T., Perkins, D., Kay-Lambkin, F., Lewin, T., \& Kelly, B. (2015). Familiarity with and intentions to use Internet-delivered mental health treatments among older, rural adults. Aging \& Mental Health, 19, 989-996. doi:10.1080/13607863.2014.981744

Ho, D. W. H., Mak, V., Kwok, T. C. Y., Au, A., \& Ho, F. K. Y. (2015). Development of a web-based training program for dementia caregivers in Hong Kong. Clinical Gerontologist, Advanced Online Edition. doi:10.1080/07317115.2015.1008155

Markle-Reid, M., \& Browne, G. (2001). Explaining the use and non-use of community-based long-term care services by caregivers of persons with dementia. Journal of Evaluation in Clinical Practice, 7(3), 271-287. doi:10.1046/j.1365-2753.2001.00306.x

Palonen, M., Kaunonen, M., \& Åstedt-Kurki, P. (2016). Exploring how to increase response rates to surveys of older people. Nurse Researcher, 23, 15-19. doi:10.7748/nr.23.5.15.s4 
Pearlin, L., Mullan, J., Semple, S., \& Skaff, M. (1990). Caregiving and the stress process: an overview of concepts and their measures. The Gerontologist, 30, 583-594. doi:10.1093/geront/30.5.583

Petty, D. (1990). Respite care: a flexible response to service fragmentation In N. Mace (Ed.), Dementia care: patient, family and community (pp. 243- 269). Baltimore: The Johns Hopkins Press.

Phillipson, L., Magee, C., \& Jones, S. C. (2013). Why carers of people with dementia do not utilise out-of-home respite services. Health \& Social Care in the Community, 21(4), 411-422. doi:10.1111/hsc.12030

Phillipson, L., Jones, S. C., \& Magee, C. (2014). A review of the factors associated with the non-use of respite services by carers of people with dementia: implications for policy and practice. Health \& Social Care in the Community, 22(1), 1-12. doi:10.1111/hsc.12036

Phillipson, L, Low, L-F, Dreyfus, S. (2019). Consumer-directed care for older Australians: Are resources identified on the Web adequate to support decisions about home-based care packages? Australian Journal of Social Issues, 54: 135- 156. doi: 10.1002/ajs4.66

Phillipson, L., Johnson, K., Cridland, E., Neville, C., Fielding, E. and Hasan, H. (2019). Knowledge, help-seeking and efficacy to find respite services: an exploratory study in help-seeking carers of people with dementia in the context of aged care reforms. BMC Geriatrics, 1, 1-9.

Ricketts, T., \& Goldsmith, L. (2005). Access in health services research: The battle of the frameworks. Nursing Outlook, 53, 274-280. doi:10.1016/j.outlook.2005.06.007 
Robinson, A., Lea, E., Hemmings, L., Vosper, G., McCann, D., Weeding, F., \& Rumble, R. (2012). Seeking respite: issues around the use of day respite care for the carers of people with dementia. Ageing and Society, 32(2), 196-218. doi:http://dx.doi.org/10.1017/S0144686X11000195

Walker, J., Crotty, B. H., O'Brien, J., Dierks, M. M., Lipsitz, L., \& Safran, C. (2017). Addressing the Challenges of Aging: How Elders and Their Care Partners Seek Information. The Gerontologist, 57(5), 955-962. doi:10.1093/geront/gnw060 